\title{
EXPLORING CONCOMITANT CONCEPTS IN THE DISCUSSION ON THE CIRCULAR ECONOMY: A BIBLIOMETRIC ANALYSIS OF WEB OF SCIENCE, SCOPUS AND TWITTER
}

\author{
Anna MIRZYŃSKA (D)1, Oskar KOSCH ${ }^{(D)}$, Martin SCHIEG (D), \\ Karel ŠUHAJDA (D) ${ }^{3}$, Marek SZARUCKI ${ }^{(D)} 1^{*}$ \\ ${ }^{1}$ Cracow University of Economics, Krakow, Poland \\ ${ }^{2}$ Technical University of Munich, Munich, Germany \\ ${ }^{3}$ Brno Technical University, Brno, Czech Republic
}

Received 16 April 2021; accepted 28 July 2021

\begin{abstract}
A growing interest in the circular economy, which is seen in the intensification of public discourse, could lead to a danger of blurring the concept and introducing inefficiency in implementing circular economy-based solutions. This study explores the trend in concomitant or accompanying concepts of the discussion about the circular economy themes understanding regarding scientific publications (3,486 publications from Web of Science and Scopus) and popular (non-scientific) domain (represented by 106,504 tweets) in the years 2011-2018. By employing text mining, we calculated the Jaccard similarity index divided into years. The results reveal changes over time in themes accompanying the circular economy discussion and a trend of rising recognition of research-related keywords in general public discussion, with unweighted similarity reaching $39.44 \%$ in 2018 . Our Twitter keyword research perspective indicates the need to consider the consumer's role in the development of the circular economy - through keywords that are closely related to consumers' daily activities.
\end{abstract}

Keywords: circular economy, sustainable development, concepts meaning, bibliometrics, Twitter.

JEL Classification: D85, M48, O30, Q56, Q57.

\section{Introduction}

The concept of circular economy (CE) is getting traction among scholars, industry representatives, and policy makers referring "as an alternative model that minimizes resource depletion, waste, and emissions" (Geissdoerfer et al., 2020, p. 1). Some regions have already implemented the idea of a CE to achieve a more sustainable consumption of natural resources, despite the observable differences in the policy articulation and even the meaning of the $\mathrm{CE}$ in these regions (McDowall et al., 2017). Regardless of growing body of research on various

*Corresponding author. E-mail: szaruckm@uek.krakow.pl

Copyright (c) 2021 The Author(s). Published by Vilnius Gediminas Technical University

This is an Open Access article distributed under the terms of the Creative Commons Attribution License (http://creativecommons. org/licenses/by/4.0/), which permits unrestricted use, distribution, and reproduction in any medium, provided the original author and source are credited. 
CE topics in the last years, it has been noticed lack of a unified definition being accepted by the researchers' community due to the intricacy of CE (Shen et al., 2020). It causes even more misunderstandings in the debate between scholars and non-scholars or the general public (audience). In order to increase the effectiveness of CE-based solutions implementation, it is of importance to decrease the gap in perception of this concept, since better recognition leads to approval and engagement in the process of practical implementation of such initiatives.

In traditional terminology exists the principle of univocity, which means that "one concept is referred to by one term (no synonymy) and one term can only refer to one concept (no polysemy)" (Temmerman, 2000, p. 60), thereby imposing to the term a specific characteristic and meaning in discourse (Sager, 1990; Temmerman, 2000). There are two primary approaches to the scientific terminology: one, which implies that terminology should be precisely defined to avoid creating the pseudo conceptions (Pushkin, 1996), and second, in which comprehensive approach to terminology fulfilled through scientific discourse leads to building the science (Lewis \& Linn, 1996). This conflict is also being debated in organization and management theory (e.g., Cannella \& Paetzold, 1994; Pfeffer, 1993). Many researchers are trying to define science through rational, strict rules and exclude the ambiguity of terminology and practical way of creating science (Latour, 1987, pp. 14-18). From the other point of view, science is defined as a flexible cultural space in which there are no significant criteria for recognizing what is scientific and non-scientific (Gieryn, 1997). This dispute about the meaning of terms for the development of science is also significant for social sciences, for which "terminology matters" (Eitzel et al., 2017). The blurriness of the concepts, which provides social values into business practice, was pointed as a primary reason for failure in applying them into the practice (Engelman, 2013; Janoušková et al., 2019; Loiseau et al., 2016; Naudé, 2011). There is plenty of theoretical and empirical evidence that achieving sustainable policy goals depends on effective communication between their stakeholders, communication in which the first step is to find a shared space of ideas meaning (Lindenfeld et al., 2012; Sartori et al., 2011; Shahzalal \& Hassan, 2019). Thus, our research focuses on the widely disputable concept of $\mathrm{CE}$ and its definition through the association network in science and popular discourse.

The main purpose of the present study is to explore the convergence of similarity of topics in the CE concept in scientific and general public discussions. We do not attempt to establish a coherent conceptual definition, but to examine a trend of association of ideas in the CE discussion. Rather we seek answering two research questions related to: 1) identifying concomitant concepts in the discussion on the circular economy in scientific and popular sources, and 2) exploring similarities and differences between bibliographic databases and posts for general audiences. Documents indexed in two bibliographical databases (Web of Science and Scopus) provided data on scientific discourse and general audience discussion is operationalized by Twitter posts (tweets).

This paper is structured as follows: Section 1 provides theoretical background related to the meaning and specifics of CE as the research object. Section 2 establishes the methodological framework to study the undertaken research problem. Section 3 presents the study results based on the bibliometric analysis of the scientific (based on WoS and Scopus) and popular (by Twitter) understanding of the CE concept. Section 4 discusses the obtained re- 
sults on the identified concomitant concepts in the debate on the CE in scientific and popular sources, as well as the existing similarities and differences between bibliographic databases and posts for general audiences. Finally, the conclusions and future research perspectives are provided.

\section{Theoretical background}

The concept of CE was coined in the 1960s by the ecological economist Boulding (1966) who argued on the superiority of the recycling waste resources approach to maximize the use of limited resources. His concept is based on approach to Earth, as a circular and closed system with limited assimilation ability. Segerson, Pearce, and Turner (1991) described the impact of the resources on the economy in two models of production and consumption, continuing this thought: linear and circular. This analysis is considered as a background for current approaches to the concept of circular economy (Andersen, 2007; Ghisellini et al., 2016; Su et al., 2013; de Pascale et al., 2021).

It should be noted that the circular economy does not have one commonly accepted definition and meaning, even in scientific studies (Lieder \& Rashid, 2016; Yuan et al., 2006). The following related concepts are the sources of various insights on CE: indicated laws of ecology (Commoner, 1971), regenerative design (Lyle, 1996), industrial ecology (Lifset \& Graedel, 2015), cradle-to-cradle design (McDonough \& Braungart, 2002), blue economy (Pauli, 2010), performance economy (Stahel, 2010). The circular economy is a well-rooted concept in the area of sustainable development (Geissdoerfer et al., 2017; Kirchherr et al., 2017; Schroeder et al., 2019; Horvath et al., 2019; Stankevičienè \& Nikanorova, 2020), waste management (Ji et al., 2018), part of the intellectual concept of the green economy (D'Amato et al., 2017), as well as supply chain (Braz et al., 2018) were heavily discussed within public policy, as well as at the level of organization and business models (Michelini et al., 2017). CE is also associated with the model of industrial symbiosis, which assumes vital business networking to create values and competitive advantages (Yazan \& Fraccascia, 2019), and industry 4.0 (Khan et al., 2021; Rajput \& Singh, 2020; Ciliberto et al., 2021). CE is also recognized as an evolving approach aiming at the sustainable usage of various raw materials and natural resources (McDowall et al., 2017), requiring a move from the traditional approach or linear model of "take, make, use and dispose/waste" to the innovative approach based on circular model of "reduce, reuse, recycle, recover, remanufacture and redesign" (Jabbour et al., 2020).

The CE follows the path depicted in publications covering the literature review on the mentioned topic (Gregorio et al., 2018) and bibliometric studies (Ruiz-Real et al., 2018). Some very specialized studies in terms of spatial criterion can be noted (Cui \& Zhang, 2018; Türkeli et al., 2018) or thematic one (Jin et al., 2019; Magrí et al., 2017; Nobre \& Tavares, 2017), which are understandable given the origins of the circular economy, which are closely related to China (e.g., Shen et al., 2020), the European Union, sustainability, and environmental issues. Some papers aim at deconstructing circular economy aspects such as meaning and associated ideas (Homrich et al., 2018; Shahzalal \& Hassan, 2019), highly essential aspects and aims of this concept (Heshmati, 2017), questions about circular economy barriers (Araujo Galvão et al., 2018) and trends (Deus et al., 2017). Interestingly, a circular way of development has become one of the European objectives in the growth strategy (Johnston, 2016). 
A plethora of meaning of a concept is identified as the main reason for ineffectiveness in implementing this kind of development idea into the business and policy practice (de Vries \& Petersen, 2009; Gladek, 2017). Albino and Fraccascia (2015) also point to the lack of a systematic view on the business environment and relationships and the business system model review. The differences between stakeholders may have the most significant influence on the course of environmental public policies, which is related to the implementation and practical approach to CE and reveals barriers of CE theory development in research and business areas (Lopes de Sousa Jabbour et al., 2018; Rajput \& Singh, 2019; Tseng et al., 2018). The theoretical impact of existing concepts on CE is also crucial in defining this idea's implementation in business and political practice (Saavedra et al., 2018). Since CE implementation requires the support of various stakeholders, including external parties (Shen et al., 2020), diverse understanding of the concept might be the reason for disagreement. It is worth mentioning that many conceptual disputes are "sustained by perfectly respectable arguments and evidence" (Gallie, 1956, p. 169), and this applies also to the CE concept (Korhonen et al., 2018 b), indicating that an agreement on CE might not be reached.

Many research pieces have focused on CE's scientific meaning, based on the available literature (Kirchherr et al., 2017). However, there is no research on the popular meaning of CE to the authors' best knowledge. We follow the call of Korhonen, Honkasalo, and Seppälä (2018a, p. 41) to study limits brought by definitions of the concept and differences in understanding the circular economy. Here, the study compares different communities formed by the separate communication platforms. At the same time, bibliographic databases are frequently used and do not need an explanation. The use of Twitter is justified by the objective of a better understanding of current societal concerns (Budak et al., 2011) because this platform is known for disseminating sustainability knowledge (Huang et al., 2019).

Studying the convergence of similarity of topics in the CE concept in scientific and general public discussions is the purpose of this scientific article. The purpose of the presented works review is not to establish a coherent conceptual definition but to examine a trend of associated ideas in the circular economy discussion. Documents indexed in Web of Science (WoS) and Scopus represent the scientific context and the general public context is exemplified by Twitter posts (tweets). Thus, the present research aims to answer two research questions:

1) Which concomitant concepts in the discussion on the circular economy in scientific and popular sources might be identified?

2) What similarities and differences in such settings exist between bibliographic databases and posts for general audiences?

It provides management theorists and practitioners with a brief overview of common $\mathrm{CE}$ themes, as seen in scientific publications and tweets for general audiences (in the text "general" is interchangeably used with the word "popular"), which would identify opportunities and challenges related to the circular economy and establish communication between companies and their consumers, leading to consumer acceptance of business models for the needs of the closed cycle. The dimension for the type of documents - publications and tweets - is also referred to in the text as realm, context, thread, and platform. 


\section{Methodology}

We followed the methodology based on an inquiry into understanding a concept presented by Dahlsrud (2008) and Kirchherr et al. (2017), who coded related topics existing in definitions into a broader semantic framework. The methodological approach adopted in this work assumes the presence of the relationship between the concepts that occur in the circular economy's context, thus creating a network depicting what $\mathrm{CE}$ consists of. Fields of science do not limit such type of connections, and such a map allows to create a coherent image of defining the concept and its context while adopting the opinions of various stakeholder groups: i.e., scientific (represented by WoS and Scopus) and popular (Twitter) understanding of the CE idea.

Therefore, the study consists of two data sources. The first, constituted by bibliographic databases, has a long history of researchers' exploitation (including sustainable development themes, e.g., Moya-Clemente et al., 2021) and does not require additional explanation. The bibliometric use of the mentioned databases is noted frequently (as they are discussed in the bibliometrics handbook, i.e., Todeschini \& Baccini, 2016, pp. 17-19). The second source, Twitter, is used less, even though it offers access to a vast database of text content and metadata. The scientific use of Twitter varies, and apart from a popular social network analysis of political issues, it includes mechanisms for the collection of real-time data in cooperation with respondents (e.g., Hingle et al., 2013), or even studying information flows during scientific conferences (e.g., Weller et al., 2011).

Twitter features keywords that start with a hash and are written without spaces called \# or hashtags defined as "unique tagging format linking Tweets to user-defined concepts" (Chang \& Iyer, 2012, p. 248). Since they are part of information-seeking behavior, which Twitter supports in connecting one object to another (Russell-Rose et al., 2014), they seem to be an excellent form of studying concepts linked together. Furthermore, Twitter appears to be most commonly used by non-scholars (Priem, 2014, p. 269), and those scholars who participate are usually linked with natural sciences; social sciences researchers, e.g., economics, sociology, and history of science, rarely use Twitter for communication (Holmberg \& Thelwall, 2014) and should not affect the results, blurring the differences between popular and scientific understanding.

Although research has been done to uncover connections between Twitter's impact and scientific impact, with contradictory results (e.g., Bornmann, 2015; Haustein et al., 2014; Priem et al., 2012; Priem \& Costello, 2010; Thelwall et al., 2013; Torres-Salinas et al., 2013), these were purely focused on impact in terms of citations, and usually in a single direction (i.e., if it is possible to foresee the citations based on tweets). They did not address the thematic and semantic impact of the research on the concepts' popular understanding. On the contrary, two significant exceptions were found, the first of which was aimed "to explore the concept of sustainability in nursing using social media” (Richardson et al., 2016, p. 1088) and resulting in, e.g., word cloud of the words extracted from the Twitter discussion. The second presented insights into the use of Twitter for the discovery of socio-semantic networks that can contribute to the discovery of the causal links (Veltri \& Atanasova, 2017). 
Based on these studies, we try to fill the methodological gap in conducting a thematic and semantic analysis of both scientific and popular concepts' understanding. In order to maintain logic, the research was conducted in three stages: (1) documents retrieval, (2) documents inclusion, and (3) documents analysis. The subsequent sections highlight the most critical aspects of each of the steps. The results of these three phases are grouped into five parts: (1) overall field statistics, (2) most prolific authors, (3) literature themes, (4) tweets themes, and (5) common themes and convergence/divergence of concept understanding.

\subsection{Documents retrieval}

Multiple database use was implemented due to single database coverage limitations (Bramer et al., 2017): Scopus and Web of Science (WoS) were selected to ensure the presence of highquality journals only.

Scopus and Web of Science (WoS) queries were executed on the 18th of January 2019:

- Scopus: TITLE-ABS-KEY ("circular economy") AND PUBYEAR < 2019

- WoS: TS=("circular economy"), Indexes=SCI-EXPANDED, SSCI, A\&HCI, CPCI-S,

CPCI-SSH, BKCI-S, BKCI-SSH, ESCI, CCR-EXPANDED, IC Timespan=1900-2018

Search strategy results are presented in Table 1, with statistics on the number of authors, sources (journals, proceedings), keywords, and countries involved.

Since the union was done with Web of Science priority, few countries are missing - e.g., the same document in Scopus included Cote d'Ivoire among other countries. However, WoS did not (another country with that issue was Nepal).

On Twitter, profiles were found to collect tweets further searching through @circular and browsing the first 68 results.

Handpicked profiles that were found to be relevant: @circecon, @CircularEcology, @circulardevices, @GoCircular, @CircularFibres, @LiveCircular, @CircularChange, @LAUNCHNordic, @CircularInnova, @LynnIWilson, @circularesummit, @IoniqaCircular, @CircularEconLab, @CircularEClub, @bioeconcircular, @UKCPNetwork, @CCD_circdesign, @CircularFashion, @CircularX, @trycircular, @CircularDesign_, @circularfoodSW, @CircularFutures, @CircularEnergy, @eifion_circular, @ExeterCircular, @CECManchester, @circ_economy, @CircEconomyNYC, @98108HI, @PolyCE_EU, @CircularLiving, @VeoliaUK, @LonCircJam, @CircularSeal, @MargrietVonno, @circular_press, @SimpEcoCircular, @ArthurtenWolde, @circular_food, @circular_pl, @SustainLeaders, @fiona_bee,

Table 1. Results of the literature search strategy

(source: own study based on Scopus and Web of Science data)

\begin{tabular}{|l|c|c|c|c|}
\hline \multicolumn{1}{|c|}{ Stage } & Web of Science & Scopus & Union & Intersection \\
\hline Literature retrieved & 2,729 & 3,144 & 4,047 & 1,826 \\
\hline Authors retrieved & 6,600 & 7,372 & 7,639 & 4,030 \\
\hline Sources retrieved & 1,065 & 1,022 & 1,642 & 289 \\
\hline Keywords retrieved & 6,085 & 6,959 & 8,163 & 4,789 \\
\hline Countries retrieved & 78 & 88 & 87 & 77 \\
\hline
\end{tabular}


@melissamazzeo, @EmmaBurlow, and other found profiles (snowballing, hashtag search): @circulareconomy, @CircularsAwards, @ellenmacarthur.

One Twitter hashtag, \#circulareconomy, was used to not deviate from any opinions or topics. Query on \#circulareconomy was performed to find all relevant hashtags - like \#circularfashion, \#circularliving, or \#zerowaste - and then a collection of users posted with those hashtags was created. Further, users' timelines were queried for the recent 3,200 tweets.

The query results formed an extensive data set of tweets, which may or may not be connected to the circular economy but were posted by people who were once connected to the subject. \#circulareconomy search was run on 23rd of January 2019 (see Table 2), retrieved 13,083 tweets (2901 that were not retweets) with first published 2019-01-13 14:07 and last 2019-01-23 14:12 with 3,195 hashtags, of which 2,104 appeared more than once. The same query was run on the 13th of February 2019 to ensure that previously identified users were not single-time involved in discussing the circular economy. The second attempt brought 10,377 tweets that formed an intersection of 1,710 machine-found relevant users. Then, with the addition of hand-found users, the final query for tweets was performed (see Table 3 )

In total, 106,504 tweets were included; retweets were treated as ordinary tweets because the overall buzz was tested, not the originality of the content.

Table 2. Results of the search for relevant Twitter users (source: own study based on Twitter)

\begin{tabular}{|l|c|c|c|c|}
\hline \multicolumn{1}{|c|}{ Query } & $31-01-2019$ & $13-02-2019$ & Union & Intersection \\
\hline \#circulareconomy tweets & 13,083 & 10,377 & 23,460 & 0 \\
\hline \#circulareconomy users & 7,449 & 6,283 & 12,022 & 1,710 \\
\hline
\end{tabular}

Table 3. Results of the search for relevant tweets (source: own study based on Twitter, retrieved on 18th of February 2019)

\begin{tabular}{|l|l|}
\hline \multicolumn{1}{|c|}{ Stage } & \multicolumn{1}{c|}{ Result } \\
\hline All selected users (intersection + handpicked) & 1,717 \\
\hline Selected users' tweets number & $3,060,028$ \\
\hline Unique tweets number & $2,637,046$ \\
\hline English tweets & $2,083,849$ \\
\hline Tweets included in the study & 106,504 \\
\hline Theme penetration & $5.11 \%$ \\
\hline Hashtags & 15,333 \\
\hline $\begin{array}{l}\text { Hashtags longer than three characters } \\
\text { (\# }+3 \text { characters minimum) }\end{array}$ & 15,190 \\
\hline $\begin{array}{l}\text { Hashtags identified from 1:5-grams based on } \\
\text { cleaned tweets text }\end{array}$ & $\begin{array}{l}6,900: 45.42 \% \text { unique hashtags were successfully } \\
\text { reverted (83.33\% of occurrences) }\end{array}$ \\
\hline $\begin{array}{l}\text { Hashtags identified with n-grams and custom } \\
\text { dictionary n-grams sequencer }\end{array}$ & $\begin{array}{l}12,471: 82.10 \% \text { unique hashtags were successfully } \\
\text { reverted (93.04\% of occurrences) }\end{array}$ \\
\hline Tweets data range & 2011-03-31 16:31:11 - 2018-12-31 22:11:03 UTC \\
\hline
\end{tabular}




\subsection{Documents inclusion}

No extraordinary steps were taken to include documents, except for the rather strict query parameter (the presence of a "circular economy" in both cases: literature and tweets) and the common years in both datasets. It narrowed the study to 3,486 publications published between 2011 and 2018.

\subsection{Documents analysis}

To evaluate convergence/divergence and similarity issue, modified Jaccard-like indexes were constructed for the condition that one set is a subset of the other. To determine the intersection of keywords extracted from publications and tweets, all of them divided the number of those found in the tweets, concerning one-year slicing. To assess structure, a weighted version of Jaccard-like index was used: $J_{w}(K)=\sum_{i=1}^{|K|} \min \left(k_{i_{p}}, k_{i t}\right) / \sum_{i=1}^{|K|} \max \left(k_{i p}, k_{i t}\right)$, where $J_{w}$ means index similarity of (K)eywords, $|K|$ is the cardinality of keywords set, $k_{i_{p}}$ is a relative share of keyword $i$ in publications, and $k_{i}$ is a relative share of keyword $i$ in tweets.

VOSviewer (van Eck \& Waltman, 2010), CiteSpace (Chen, 2006) were used in preliminary research and bibliometrix (Aria \& Cuccurullo, 2017) R (R Development Core Team, 2018) package in the research afterwards. Document-term matrix creation was done with text2vec (Selivanov \& Wang, 2018). Parts-of-speech tagging with UDPipe (Wijffels, 2018), tweets were collected using rtweet (Kearney, 2018), tokenized with the use of tokenizer package (Mullen et al., 2018). Hashtags are deemed to contain additional information (e.g., Bansal et al., 2015; Sharmila \& Sujatha, 2016) and therefore had to be reverted to their multi-word version, and at least four methods can be utilized for such a case (Çelebi \& Ozgür, 2016). This study uses n-gram (1 to 5-gram) synthetic hashtags creator, which was boosted with the additional use of unigram sequencer (Maximum Known Matching, see Reuter et al., 2016) based on the English dictionary. Because the "circular economy" keyword and \#circulareconomy hashtag were present in all records, they were omitted in the analysis. The evolution of the most popular themes was provided to supplement the similarity index with examples of trends in keywords and hashtags.

\section{Results}

\subsection{Overall field statistics}

A study of the state of the field and general development is necessary for further analysis of thematic dynamics and allows drawing more informed conclusions. Necessary information about the field productivity is presented in Table 4 .

The number of documents is steadily growing, with a slight recession in 2012-2013. Both in per-year and cumulated versions, documents productivity remains relatively steady and should be viewed as typical for the social sciences field (Pulgarín, 2012). In the case of tweets, productivity only supports the selection of the profiles used for retrieving tweets. However, it cannot describe the average productivity of a user interested in the circular economy since tweets collection gathering relied on retrieving users' tweets, not tweets for the \#circulareconomy hashtag. 
Table 4. Productivity in the field of the circular economy (source: own study based on Web of Science, Scopus, and Twitter)

\begin{tabular}{|c|c|c|c|c|c|c|c|c|}
\hline Year & $\begin{array}{c}\text { Docu- } \\
\text { ments } \\
\text { number }\end{array}$ & $\begin{array}{c}\text { Docu- } \\
\text { ments } \\
\text { credits }\end{array}$ & $\begin{array}{c}\text { Docu- } \\
\text { ments } \\
\text { authors }\end{array}$ & $\begin{array}{c}\text { Docu- } \\
\text { ments pro- } \\
\text { ductivity }\end{array}$ & $\begin{array}{c}\text { Documents } \\
\text { productivity } \\
\text { cumulated }\end{array}$ & $\begin{array}{c}\text { Tweets } \\
\text { number }\end{array}$ & $\begin{array}{c}\text { Tweets } \\
\text { au- } \\
\text { thors }\end{array}$ & $\begin{array}{c}\text { Tweets } \\
\text { productiv- } \\
\text { ity }\end{array}$ \\
\hline 2011 & 183 & 460 & 310 & 1.484 & 1.484 & 35 & 1 & 35.000 \\
\hline 2012 & 133 & 331 & 261 & 1.268 & 1.631 & 58 & 14 & 4.143 \\
\hline 2013 & 129 & 352 & 267 & 1.318 & 1.767 & 353 & 41 & 8.610 \\
\hline 2014 & 173 & 458 & 349 & 1.312 & 1.830 & 1,492 & 99 & 15.071 \\
\hline 2015 & 203 & 606 & 522 & 1.161 & 1.761 & 7,143 & 245 & 29.155 \\
\hline 2016 & 498 & 1,571 & 1,274 & 1.233 & 1.644 & 11,211 & 362 & 30.970 \\
\hline 2017 & 876 & 3,039 & 2,495 & 1.218 & 1.581 & 23,616 & 602 & 39.229 \\
\hline 2018 & 1,291 & 4,794 & 3,872 & 1.238 & 1.586 & 62,596 & 1,502 & 41.675 \\
\hline ALL & $\mathbf{3 , 4 8 6}$ & $\mathbf{1 1 , 6 1 1}$ & $\mathbf{7 , 3 2 1}$ & - & - & $\mathbf{1 0 6 , 5 0 4}$ & $\mathbf{1 , 5 2 3}$ & - \\
\hline
\end{tabular}

\subsection{Most prolific authors}

The most prolific authors, both of documents and tweets, have been identified. In the case of Web of Science and Scopus, in the studied period, the following researchers authored or coauthored the most considerable quantity of documents (above 16, the number is given in the parentheses): (42) Wang Y., (41) Geng Y., (36) Wang H., (28) Li Y., (28) Liu Y., (28) Zhang Y., (25) Li J., (24) Li W., (23) Wang X., (22) Zhang H., (21) Zhang J., (19) Wang J., (18) Liu J., (18) Liu X., (18) Liu Z., (18) Wang L., (18) Zhao J., (17) Bocken N., (16) Qi J. They are primarily affiliated in Asian countries, particularly in China. These authors show substantially higher productivity than the rest of the collection - 2.694 - and out of 492 works of which they are authors or co-authors, only $44(8.943 \%)$ were written by one author. The most co-authored paper has 25 co-authors (but only one of them is listed above).

The most productive nicknames were acquired in the studied collection of tweets obtained from the previously identified users. The cut-off value consisted of 616 tweets posted in the studied period - the exact values are enclosed in parentheses; the most prolific users' nicknames are: $(1,838)$ circulareconomy, $(1,413)$ ValuedCircEcon, $(1,349)$ circularesummit, $(1,163)$ CircularEClub, (1,140) AlexLemille, (931) DrResources, (926) circleeconomy, (925) jossbleriot, (841) PBarczak, (777) Enviromate_UK, (752) Julia_Vol, (742) CircularEconLab, (720) PressRestore, (705) circulairNL, (692) ArthurtenWolde, (669) thinkDIF, (641) CircularsAwards, (624) RenewableMatter, (617) ZeroWasteScot, and (616) CircularDsgNrb. Most of them are organizations' accounts (similarly to the "circulareconomy"), but private accounts (like Julia__Vol) do also contribute to the discussion on the circular economy on Twitter.

These authors and users should attract researchers' attention in case of further investigations on the circular economy field. That comes with a warning that productivity was measured only in terms of quantity, not impact (e.g., citations, degree) that authors possess and should be viewed as inferior to in-depth bibliometric analysis. 


\subsection{Literature themes}

The list of issues that capture researchers' attention is constantly changing and is vast. Of 7,269 distinct keywords identified from 2011 through 2018, only 1,584 occurred more than once. To capture the evolution of the themes identified in the literature, the 50 most occurring keywords phrases were selected. The changes of their relative importance (expressed as the ratio of occurrence in a given year to all keywords occurrences, the width of lines stands for the relative importance) are depicted in Figure 1.

The first and most noticeable change in the literature is the transition from "sustainable development" to the "sustainability" keyword used 259 times. The least used keyword among these 50 was "supply chain management", with 17 occurrences. Other keywords that once were the most exposed, but lately lost importance, are: "China", "industrial symbiosis", "reverse logistics", "eco-efficiency", "material flow analysis", "eco-industrial park/s", "environment", "cleaner production", "climate change", "product design", "green economy". The average time of all occurrences is presented in Figure 1 as circles. Keywords gaining researchers' interest in the recent time may be identified: "sustainability", "recycling", "waste management", "life cycle assessment (lca)", "resource efficiency", "remanufacturing", "waste", "anaerobic digestion", "biogas" (regaining interest), "innovation", "bioeconomy”, "business model/s", "renewable energy", "food waste", "municipal solid waste" (regaining interest), "eco-innovation" (rather slight increase), "pyrolysis" (regaining interest), "business model innovation". There are also one-time keywords, like "WEEE" (European Union regulation "The Waste Electrical and Electronic Equipment Directive") or possibly "anaerobic digestion". Industrial symbiosis, eco-industrial parks, environmental protection, green economy, and evaluation evolved into more generic sustainability and bio-economy. These are associations resulting from the EU influence on CE (Saavedra et al., 2018). More attention is given to the solutions on single organization level; innovation, business model, remanufacturing, and packaging are the keywords that indicate the emergence of this dimension. A new trend is related to energy: anaerobic digestion, biogas, renewable energy, pyrolysis, and in some parts, food waste. Some concepts, like product design, have lost their importance to more detailed solutions. Such changes allow examining temporal patterns and bringing their presence in other types of written sources. For such reason, the analogous analysis of tweets is presented in the subsequent section.

\subsection{Tweets themes}

As in the previous section, a temporal analysis of tweets was conducted based on keyword research - in the context of Twitter, these are hashtags. The most popular ones, with alterations regarding the relative importance, are presented in Figure 2.

The first and the most critical difference between keywords and hashtags dynamics is the possibility for the hashtag to obtain the first position in rank within a single year of use - as it was in the case of \#beatplasticpollution, that in the studied dataset was mentioned 7,255 times in 2018. Among the top 50 list, the least used hashtag was \#iot (internet of things), with 493 occurrences. 


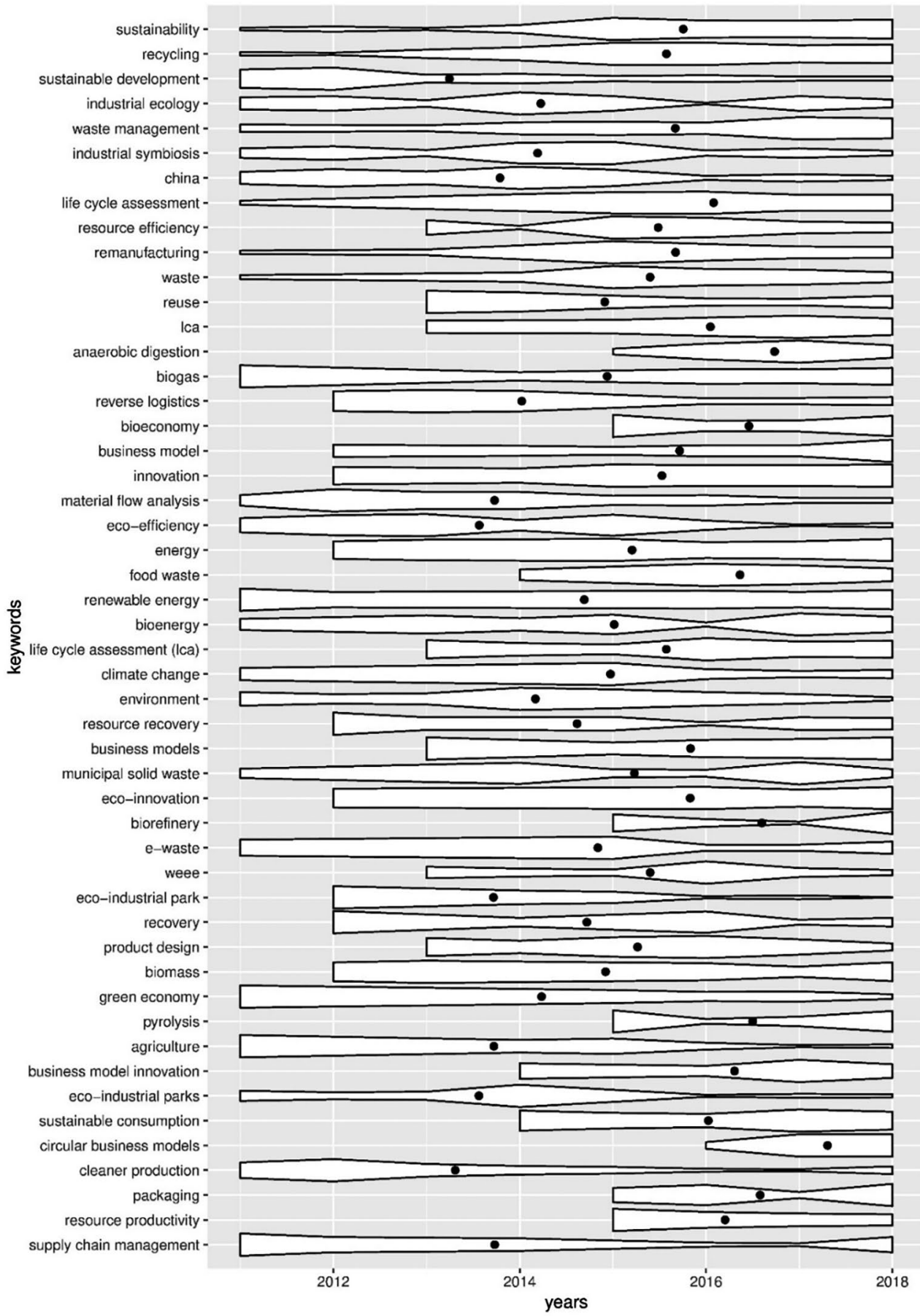

Figure 1. Normalized ribbon graph of the top 50 keywords (by occurrences), the evolution of relative importance (2011-2018) illustrated by width (source: own study based on Web of Science and Scopus) 


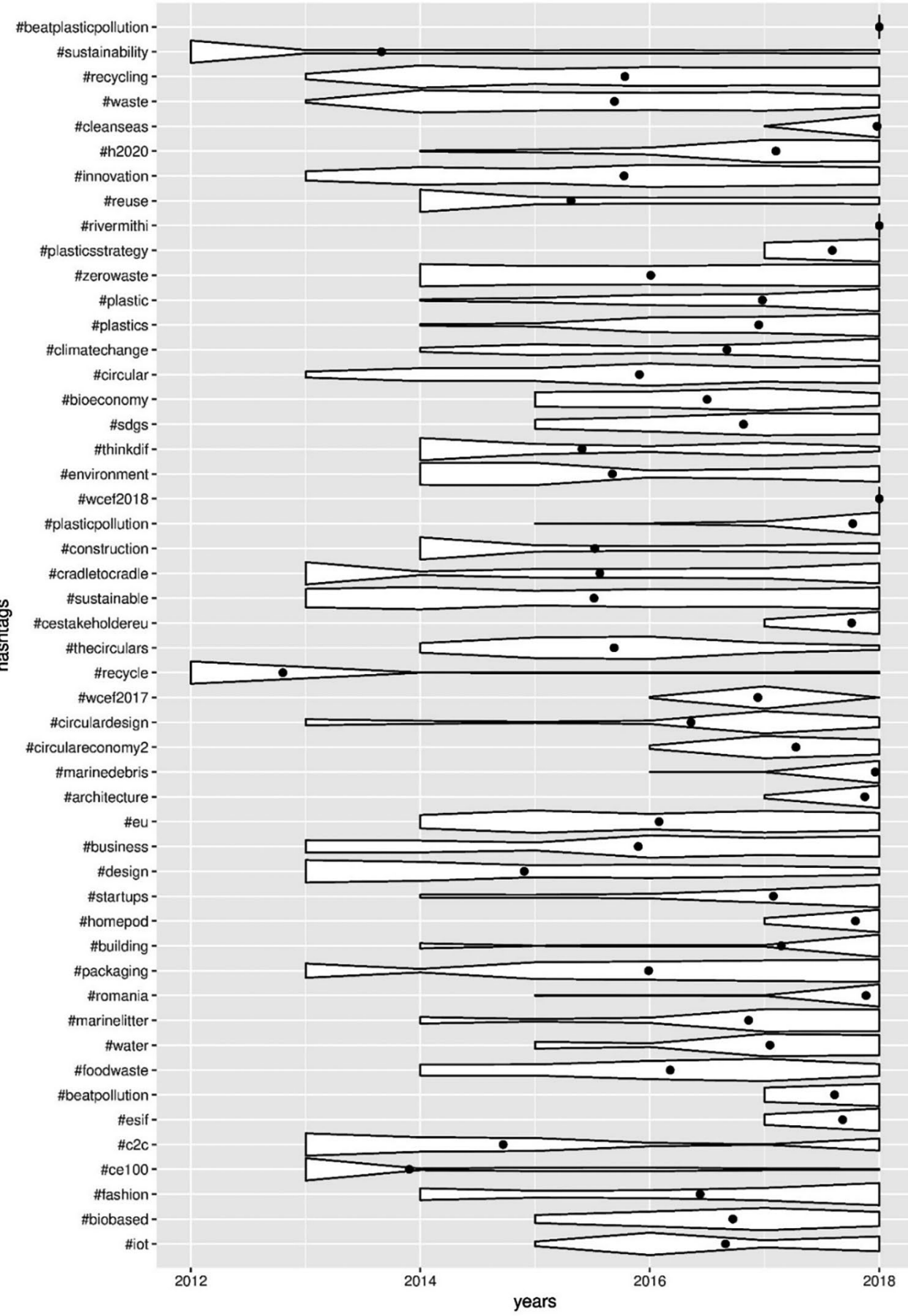

Figure 2. Normalized ribbon graph of the top 50 hashtags (by occurrences), the evolution of relative importance (2012-2018) illustrated by width (source: authors' own study based on Twitter) 
Two other keywords stormed tweets: \#rivermithi (about pollution of the Mithi River in India) and \#wcef2018 (World Circular Economy Forum 2018). The rise and fall of public opinion interest is sharply denoted in Twitter and the decreasing hashtags are as follows: \#sustainability, \#thinkdif, \#environment, \#construction, \#recycle, \#design, \#c2c (cradle-tocradle), \#ce100, \#iot. The increase in the interest may be seen in the following hashtags: \#cleanseas, \#h2020, \#plasticsstrategy, \#plastic(s), \#bioeconomy, \#sdgs (Sustainable Development Goals), \#plasticpollution, \#cestakeholdereu, \#business, \#startups, \#homepod, \#building, \#romania, \#marinelitter, \#water, \#beatpollution, \# esif (European Structural and Investment Funds), \#fashion. During the period under review, some hashtags were very popular all the time: \#recycling, \#waste, \#innovation, \#zerowaste, \#circular, \#sustainable, \#eu, \#packaging, \#foodwaste. Overall, dynamics are seen to be more intense on Twitter; however, it is also possible for hashtags to persist over time. Waste, recycling, innovation, and sustainable incentives are examples of such hashtags.

When compared to the themes identified in the publications, the most significant difference is in higher attention paid to the problem of litter and pollution - while publications are concerned with providing the solutions to mitigate the risk of the overuse of the Earth's resources, tweets are more concerned with providing updates on issues of waste. Such a situation brings a risk that both communities will recognize each other ideas but will fail to structure the discussion with the same amount of attention paid to each problem. It may lead to a misalignment between the main discussion flows in different groups and prevent researchers from creating socially acceptable and valuable solutions. The issue of similarity of the discussion in the scientific and popular context is presented in the next section.

\subsection{Common themes and convergence/divergence}

Changes in the occurrence of keywords and hashtags on the individual level have shown that some topics may emerge through time, while others decline; for such reason, it is possible to track permutations in the similarity of discussion conducted both in social media (i.e., Twitter) and scientific literature, as retrieved with bibliographic databases, sliced by years. The evolution of Jaccard-like similarity of publications' keywords in tweets and publications is depicted in Figure 3.

Of the two versions calculated, the unweighted similarity shows recognition of scientific keywords in tweets (i.e., if they were present). The weighted one provides information on the structure - how many discussions are alike in terms of frequency of specific keywords. Therefore, the unweighted version captures the issue of recognizing problems, while weighted gives hints about the discussion's overall similarity. In the studied case, the initially very low recognition of science problems grows over time (reaching $39.44 \%$ in 2018) - and most certainly, it is the result of an increasing number of tweets mentioning circular economy. The structure, however, remains stable and low; the issues get different attention in data sources, with a mean of $10.31 \%$ for the studied period.

Another direction of the study - to check publications abstracts and tweets for the presence of segmented Twitter hashtags - is displayed in Figure 4. 


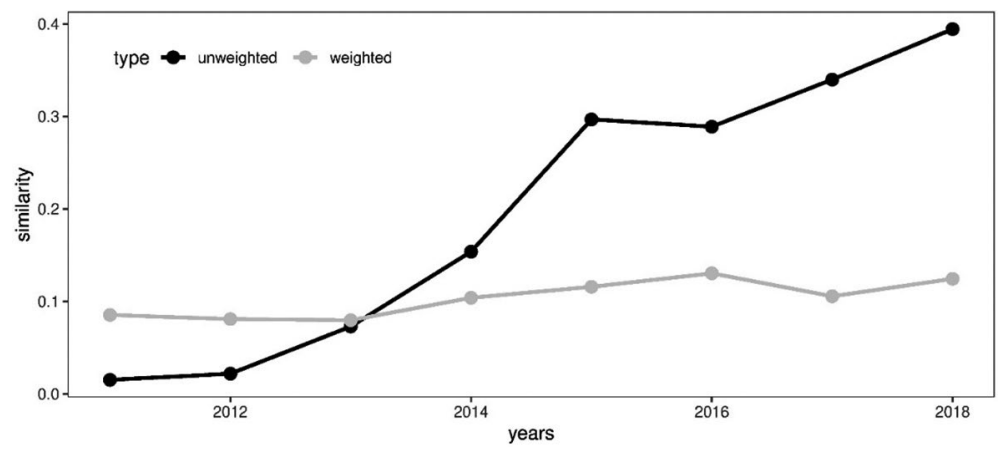

Figure 3. The similarity in the publications' keywords presence in both publications and tweets (2012-2018) (source: own study based on Web of Science, Scopus, and Twitter)

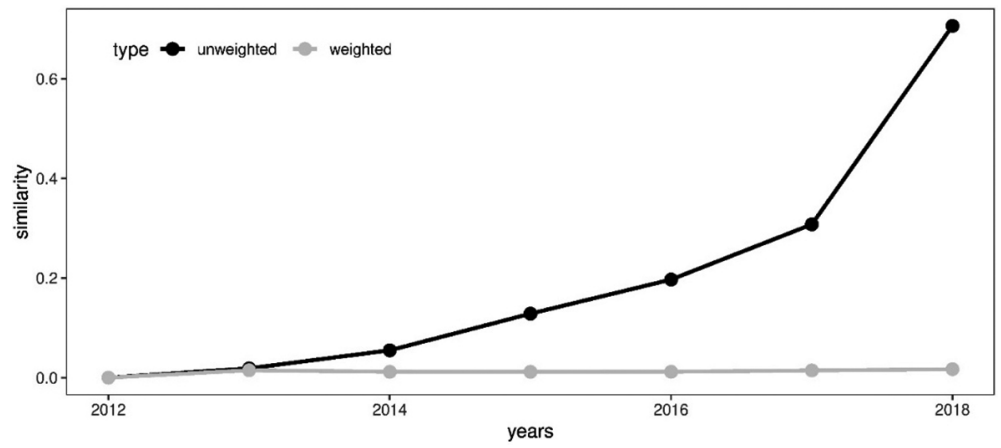

Figure 4. The similarity in tweets' hashtags presence in both publications and tweets (2012-2018) (source: own study based on Web of Science, Scopus, and Twitter)

In this case, the issues' recognition achieves a high level of $70.69 \%$ but contrasts with the extremely low similarity of structure that oscillates around $1.50 \%$. The situation probably can be explained by the fact that it is relatively easy to find segmented hashtags in abstracts. However, scientific texts can get away from the number of hashtags and their colloquial nature, leading to searching abstracts for simple words. Another reason may be the academics' reluctance and difficulties to approach management problems from a more hands-on, common-sense approach that is valued in the Twitter environment.

Otherwise, the top-ranked keywords and hashtags from previous sections might be compared. As far as convergence goes, both sources capture a decrease of interest in general environmental issues, product design, cleaner production, and cradle-to-cradle. Topics that are gaining interest include business, business models, startups, innovations, life cycle assessment, and bio-economy. The group with at least stability in both sources consists of different waste issues: food waste, packaging, recycling, and the "zero waste" concept. Furthermore, the last group that shows differences consists of stable problems or trends on Twitter, but without much attention in scientific publications. These are the ones that replaced the environment with more specific issues: clean seas, plastic pollution, and strategy on mitigating it, water resources, marine litter, Mithi River, and World Circular Economy Forum. 


\section{Discussion}

Results show almost $40 \%$ presence of scientific keywords in the tweets, suggesting that scientific discussion is recognized among Twitter users; this is not to judge if this recognition comes with understanding. Simultaneously, poor structure with weighted similarity ca. $10 \%$ suggests that the attention given in these two contexts is unbalanced. A starting point for both threads of discussion is sustainability, as this is the term that frequently occurred in colloquial and scientific discussions. Defining the circular economy with vague concepts that are not widely recognized in both realms poses a threat to further operationalization of the term in global practices. A solution to that issue is an attempt to find a common ground. Thus, it may serve that Twitter users and researchers describe CE through practical words, ecological associations, and innovative approach. This understanding may not have many words in common, but the underlying manner of creating associations is similar; resemblance could also be found in references to historically combined theories of socio-economic development, as well as ecological sensitivity. However, this does not mean a guarantee of success in introducing $\mathrm{CE}$ as a business and public way to develop the harmony of society and the environment. The growing popularity of CE means an increased number of its stakeholders. Referring to the European Commission's plans, public policymakers should pay particular attention to the quality and consistency of messages about CE. The concept should also be better described in terms of changes it requires and the barriers encountered. For that reason, the publication of Diaz Lopez, Bastein, and Tukker (2019) might be used, but with a further inquiry into the obstacles caused by a different understanding of the concept among different stakeholders.

Different groups of important keywords among publications and tweets were captured. The most relevant scientific keywords are connected to the production process, especially to production resources and management. On the other hand, tweets have a stronger association with stakeholders and groups of interests, mostly related to European strategy and development terms. The association on Twitter of CE changed from a broad perspective like sustainability, recycling construction or design to a more detailed functional meaning through the last years. Based on the decreasing usage trend of \#thinkdif and growing of \#business, \#startups, \#sdgs, it could be assumed that CE was implemented into business, policy thinking, and models. The keywords continuously used are related to business or policy, as well as to customers or households. It could add to the conclusion about the differences between CE on Twitter and the research field bibliographic databases. The former is more functional and encourages a broader group of stakeholders. The latter is mainly concerned with the production, production system, and production resources related to the idea of manufacturing in a circular way.

The analysis shows the convergence in the similarity of themes assisting CE and occurring keywords, e.g., the growing trend of using on both the scientific and popular platform has been observed for "waste management" and "bio-economy". The association with the idea of sustainable development was substantially more often presented in research publications. Tweets, on the other hand, focused on the more specific phrase "sdgs". The CE defining through the "blue economy" or "ecology laws" has not been observed in the top 
50 keywords, while the "supply chain" gained relatively low interest. The concept of "industrial symbiosis", which can be recognized as CE implementation into business practice, has been losing relative importance in publications, and tweets have not reported its frequent use. The obtained keywords results coincide with the conclusion about the CE understanding sources: ecological and environmental economics and industrial ecology (Ghisellini et al., 2016). The decreasing trend of "China" as a keyword is also significant, which after the massive attention given to the $\mathrm{CE}$ model in this country, may suggest that the issue is no longer relevant. The lack of keywords about the EU and its policy or strategy is shown on Twitter, where the popularity of using CE in association with UE is a constant and robust trend. The described observation confirmed the geographic concentration of CE development. Kirchherr et al. (2017) pointed the role of China in CE defining. The authors also emphasize the possible fear of defining CE through the "reduce" phrase in the popular circular economy definition. This observation is consistent with the research results presented, in which the word "reduce" or similar was not observed. Our analysis confirms the strong association between the word "sustainability" and CE.

However, there is a broad conclusion about CE's neglected area, the one from a consumer perspective, in scientific publications. Our perspective of Twitter keyword research indicates the possibility of considering the consumer's role in the implementation of CE - through keywords that are closely related to the daily activities of consumers. At this level of the analysis, it is also impossible to agree with the CE definition concept proposed by Homrich et al. (2018). The most relevant keywords did not concentrate around empirical examples of $\mathrm{CE}$, and what is even more critical; the defining circular economy through the "eco-park" association is decreasing.

Closely linked with consumers' daily activities, e.g., those connected with food waste, are business models. The first step of providing the CE business model taxonomy is to define the value network for the environment and to propose the customer interface according to the circular concept of the economy (Fraccascia et al., 2019).

One of the identified trends rising among publications is related to circular economy business models, typology, and future challenges (Diaz Lopez et al., 2019; Lüdeke-Freund et al., 2019). It, however, comes with low interest in business models from the popular perspective. Tweets discussing organization level aspects of the circular economy focused on waste and pollution. The companies should ensure that the target segment understands the benefits and the business model enough to take responsibility. Such actions are part of business models' customer interface and can be addressed using marketing science (Boons \& Lüdeke-Freund, 2013).

Because of the differences between topics in publications and tweets, it should be stated that limits posed on circular economy development by social and cultural definitions, as discussed by Korhonen et al. (2018a, 2018b), can also be a problem in the context of different communication channels, limiting the possibility of engaging a wider audience with a clear message if we use only scientific understanding. Circular production and consumption require the common ground for values of both the supply and demand. Our study may act as a cornerstone for introducing socially understandable and acceptable circular business models.

These obstacles were recognized as restraining forces in further circular economy development, mainly affecting the slow increase of acceptance of circular business models identi- 
fied in the literature (de Jesus \& Mendonça, 2018, p. 83), for they are not a subject of discussion. For broader acceptance - at least in social media like Twitter - the message should be expressively connected to solving waste, litter, and pollution problems. It seems that our comprehensive discussion has provided answers to the research questions formulated in section 2 and fulfilled the undertaken research objective.

\section{Conclusions}

Overall, our analyses show changes over time in topics related to the circular economy discussion. The present results indicate an existing trend of growing recognition of researchrelated keywords in general public discussion, supported by unweighted similarity of almost $40 \%$ in 2018. Moreover, the conducted Twitter keyword research perspective points to the need to acknowledge the consumer's role in the advancement of the circular economy by utilizing keywords closely linked to consumers' daily activities. The above provided discussion has revealed several important implications for both scientists dealing with circular economy and policy makers responsible for the implementation of this concept into practice.

Despite its scientific value-added, our research has several limitations that should be addressed in further studies. It should be noted that the hashtags segmentation used in the preparation stage is not perfect. The measurement method is asymmetric, which means science keywords were searched in tweets full-texts, but tweets hashtags were not searched in scientific literature full-texts, only in abstracts. The tweets selection may be replaced by using a paid collection of all tweets mentioning the circular economy or its related terms (although the research's longitudinal character may be lost). This study was conducted at a time of rapid development of circular economy literature. This increase urged us to conduct the research, but was also a limitation, since new documents were published. Regular checks to capture circular economy evolution should be performed using a similar procedure to this proposed here to allow data slicing for years to come.

One possible research proposition is to extend circular economy exploration with one of the themes identified as significant to the circular economy concept, to identify the common ground and applicability of theoretical constructs in the real-life context, e.g., business models, sustainable consumption or industry 4.0. Other directions are: to study relations between scientific publications and social media posts, to search for lag patterns and opportunities for content creation and academic research, to study differences in the keywords complementary for the circular economy and hashtags on Twitter, which occur in various locations, to provide an in-depth clustering on concepts connected to the circular economy with their analysis in spatial and temporal terms, the studies on specific business models and their acceptance, and customer interface as expressed on social media platforms, including Twitter.

\section{Acknowledgements}

We would like to thank all anonymous reviewers who contributed to the improvement of our paper. 


\section{Funding}

This project has been financed by the Ministry of Science and Higher Education within the "Regional Initiative of Excellence" Program for 2019-2022. Project no. 021/RID/2018/19. Total financing: 11897131.40 PLN.

\section{Disclosure statement}

Authors did not have any competing financial, professional, or personal interests from other parties.

\section{References}

Albino, V., \& Fraccascia, L. (2015). The Industrial Symbiosis approach: A classification of business models. Procedia Environmental Science, Engineering and Management, 2(3), 217-223. https:// www.researchgate.net/publication/283509018_The_Industrial_Symbiosis_approach_a_classification_of_business_models

Andersen, M. S. (2007). An introductory note on the environmental economics of the circular economy. Sustainability Science, 2(1), 133-140. https://doi.org/10.1007/s11625-006-0013-6

Araujo Galvão, G. D., De Nadae, J., Clemente, D. H., Chinen, G., \& De Carvalho, M. M. (2018). Circular economy: Overview of barriers. Procedia CIRP, 73, 79-85.

https://doi.org/10.1016/j.procir.2018.04.011

Aria, M., \& Cuccurullo, C. (2017). bibliometrix: An R-tool for comprehensive science mapping analysis. Journal of Informetrics, 11(4), 959-975. https://doi.org/10.1016/j.joi.2017.08.007

Bansal, P., Bansal, R., \& Varma, V. (2015). Towards deep semantic analysis of hashtags. In A. Hanbury, G. Kazai, A. Rauber, \& N. Fuhr (Eds.), Lecture notes in computer science: Vol. 9022. Advances in information retrieval (pp. 453-464). Springer. https://doi.org/10.1007/978-3-319-16354-3_50

Boons, F., \& Lüdeke-Freund, F. (2013). Business models for sustainable innovation: State-of-the-art and steps towards a research agenda. Journal of Cleaner Production, 45, 9-19. https://doi.org/10.1016/j.jclepro.2012.07.007

Bornmann, L. (2015). Alternative metrics in scientometrics: A meta-analysis of research into three altmetrics. Scientometrics, 103(3), 1123-1144. https://doi.org/10.1007/s11192-015-1565-y

Boulding, K. E. (1966). The economics of the coming spaceship earth. In H. Jarrett (Ed.), Environmental quality in a growing economy, resources for the future (pp. 3-14). Johns Hopkins University Press.

Bramer, W. M., Rethlefsen, M. L., Kleijnen, J., \& Franco, O. H. (2017). Optimal database combinations for literature searches in systematic reviews: A prospective exploratory study. Systematic Reviews, 6(1), 245. https://doi.org/10.1186/s13643-017-0644-y

Braz, A. C., De Mello, A. M., de Vasconcelos Gomes, L. A., \& de Souza Nascimento, P. T. (2018). The bullwhip effect in closed-loop supply chains: A systematic literature review. Journal of Cleaner Production, 202, 376-389. https://doi.org/10.1016/j.jclepro.2018.08.042

Budak, C., Agrawal, D., \& El Abbadi, A. (2011). Structural trend analysis for online social networks. Proceedings of the VLDB Endowment, 4(10), 646-656. https://doi.org/10.14778/2021017.2021022

Cannella, A. A., \& Paetzold, R. L. (1994). PFEFFER'S barriers to the advance of organizational science: A rejoinder. Academy of Management Review, 19(2), 331-341. https://doi.org/10.5465/amr.1994.9410210755 
Çelebi, A., \& Ozgür, A. (2016). Segmenting hashtags using automatically created training data. In Proceedings of the $10^{\text {th }}$ International Conference on Language Resources and Evaluation, LREC 2016 (pp. 2981-2985). https://aclanthology.org/L16-1476.pdf

Chang, H. C., \& Iyer, H. (2012). Trends in Twitter hashtag applications: Design features for value-added dimensions to future library catalogues. Library Trends, 61(1), 248-258. https://doi.org/10.1353/lib.2012.0024

Chen, C. (2006). CiteSpace II: Detecting and visualizing emerging trends and transient patterns in scientific literature. Journal of the American Society for Information Science and Technology, 57(3), 359-377. https://doi.org/10.1002/asi.20317

Ciliberto, C., Szopik-Depczyńska, K., Tarczyńska-Łuniewska, M., Ruggieri, A., \& Ioppolo, G. (2021). Enabling the Circular Economy transition: A sustainable lean manufacturing recipe for Industry 4.0. Business Strategy and the Environment, 1-18. https://doi.org/10.1002/bse.2801

Commoner, B. (1971). The closing circle: Nature, man, and technology. Random House.

Cui, T., \& Zhang, J. (2018). Bibliometric and review of the research on circular economy through the evolution of Chinese public policy. Scientometrics, 116(2), 1013-1037.

https://doi.org/10.1007/s11192-018-2782-y

D’Amato, D., Droste, N., Allen, B., Kettunen, M., Lähtinen, K., Korhonen, J., Leskinen, P., Matthies, B. D., \& Toppinen, A. (2017). Green, circular, bio economy: A comparative analysis of sustainability avenues. Journal of Cleaner Production, 168, 716-734. https://doi.org/10.1016/j.jclepro.2017.09.053

Dahlsrud, A. (2008). How corporate social responsibility is defined: An analysis of 37 definitions. Corporate Social Responsibility and Environmental Management, 15(1), 1-13. https://doi.org/10.1002/csr.132

de Jesus, A., \& Mendonça, S. (2018). Lost in transition? Drivers and barriers in the eco-innovation road to the circular economy. Ecological Economics, 145, 75-89.

https://doi.org/10.1016/j.ecolecon.2017.08.001

de Pascale, A., Arbolino, R., Szopik-Depczyńska, K., Limosani, M., \& Ioppolo, G. (2021). A systematic review for measuring circular economy: The 61 indicators. Journal of Cleaner Production, 281, 124942. https://doi.org/10.1016/j.jclepro.2020.124942

de Vries, B. J. M., \& Petersen, A. C. (2009). Conceptualizing sustainable development. An assessment methodology connecting values, knowledge, worldviews and scenarios. Ecological Economics, 68(4), 1006-1019. https://doi.org/10.1016/j.ecolecon.2008.11.015

Deus, R. M., Savietto, J. P., Battistelle, R. A. G., \& Ometto, A. R. (2017). Trends in publications on the circular economy. Espacios, 38(58), 20. https://repositorio.unesp.br/handle/11449/179432

Diaz Lopez, F. J., Bastein, T., \& Tukker, A. (2019). Business model innovation for resource-efficiency, circularity and cleaner production: What 143 cases tell us. Ecological Economics, 155, 20-35. https://doi.org/10.1016/j.ecolecon.2018.03.009

Eitzel, M. V., Cappadonna, J. L., Santos-Lang, C., Duerr, R. E., Virapongse, A., West, S. E., Kyba, Ch. C. M., Bowser, A., Cooper, C. B., Sforzi, A., Metcalfe, A. N., Harris, E. S., Thiel, M., Haklay, M., Ponciano, L., Roche, J., Ceccaroni, L., Shilling, F. M., Dörler, D., Heigl, F., Kiessling, T., Davis, B. Y., \& Jiang, Q. (2017). Citizen science terminology matters: Exploring key terms. Citizen Science: Theory and Practice, 2(1), 1-20. https://doi.org/10.5334/cstp.96

Engelman, R. (2013). Beyond sustainababble. In Worldwatch Institute (Eds.), State of the World 2013 (pp. 3-16). Island Press. https://doi.org/10.5822/978-1-61091-458-1_1

Fraccascia, L., Giannoccaro, I., \& Albino, V. (2019). Business models for industrial symbiosis: A taxonomy focused on the form of governance. Resources, Conservation and Recycling, 146, 114-126. https://doi.org/10.1016/j.resconrec.2019.03.016 
Gallie, W. B. (1956). Essentially contested concepts. Proceedings of the Aristotelian Society, 56(1), 167-198. https://doi.org/10.1093/aristotelian/56.1.167

Geissdoerfer, M., Pieroni, M. P. P., Pigosso, D. C. A., \& Soufani, K. (2020). Circular business models: A review. Journal of Cleaner Production, 277, 123741. https://doi.org/10.1016/j.jclepro.2020.123741

Geissdoerfer, M., Savaget, P., Bocken, N. M. P., \& Hultink, E. J. (2017). The Circular Economy - A new sustainability paradigm? Journal of Cleaner Production, 143, 757-768. https://doi.org/10.1016/j.jclepro.2016.12.048

Ghisellini, P., Cialani, C., \& Ulgiati, S. (2016). A review on circular economy: The expected transition to a balanced interplay of environmental and economic systems. Journal of Cleaner Production, 114, 11-32. https://doi.org/10.1016/j.jclepro.2015.09.007

Gieryn, T. F. (1997). Boundaries of science. In A. I. Tauber(Ed.), Science and the quest for reality. Main trends of the modern world (pp. 293-332). Palgrave Macmillan. https://doi.org/10.1007/978-1-349-25249-7_12

Gladek, E. (2017). The seven pillars of the circular economy - From linear to circular. https://www.metabolic.nl/news/the-seven-pillars-of-the-circular-economy/

Gregorio, V. F., Pié, L., \& Terceño, A. (2018). A systematic literature review of bio, green and circular economy trends in publications in the field of economics and business management. Sustainability, 10(11), 4232. https://doi.org/10.3390/su10114232

Haustein, S., Peters, I., Sugimoto, C. R., Thelwall, M., \& Larivière, V. (2014). Tweeting biomedicine: An analysis of tweets and citations in the biomedical literature. Journal of the Association for Information Science and Technology, 65(4), 656-669. https://doi.org/10.1002/asi.23101

Heshmati, A. (2017). A review of the circular economy and its implementation. International Journal of Green Economics, 11(3-4), 251-288. https://doi.org/10.1504/IJGE.2017.089856

Hingle, M., Yoon, D., Fowler, J., Kobourov, S., Schneider, M. L., Falk, D., \& Burd, R. (2013). Collection and visualization of dietary behavior and reasons for eating using twitter. Journal of Medical Internet Research, 15(6), e125. https://doi.org/10.2196/jmir.2613

Holmberg, K., \& Thelwall, M. (2014). Disciplinary differences in Twitter scholarly communication. Scientometrics, 101(2), 1027-1042. https://doi.org/10.1007/s11192-014-1229-3

Homrich, A. S., Galvão, G., Abadia, L. G., \& Carvalho, M. M. (2018). The circular economy umbrella: Trends and gaps on integrating pathways. Journal of Cleaner Production, 175, 525-543. https://doi.org/10.1016/j.jclepro.2017.11.064

Horvath, B., Khazami, N., Ymeri, P., \& Fogarassy, C. (2019). Investigating the current business model innovation trends in the biotechnology industry. Journal of Business Economics and Management, 20(1), 63-85. https://doi.org/10.3846/jbem.2019.6880

Huang, L., Clarke, A., Heldsinger, N., \& Tian, W. (2019). The communication role of social media in social marketing: A study of the community sustainability knowledge dissemination on LinkedIn and Twitter. Journal of Marketing Analytics, 7(2), 64-75. https://doi.org/10.1057/s41270-019-00053-8

Jabbour, C. J. C., Fiorini, P. D. C., Ndubisi, N. O., Queiroz, M. M., \& Piato, É. L. (2020). Digitallyenabled sustainable supply chains in the 21st century: A review and a research agenda. Science of the Total Environment, 725, 138177. https://doi.org/10.1016/j.scitotenv.2020.138177

Janoušková, S., Hák, T., Nečas, V., \& Moldan, B. (2019). Sustainable development - A poorly communicated concept by mass media. Another challenge for SDG. Sustainability, 11(11), 3181. https://doi.org/10.3390/su11113181

Ji, L., Liu, C., Huang, L., \& Huang, G. (2018). The evolution of Resources Conservation and Recycling over the past 30 years: A bibliometric overview. Resources, Conservation and Recycling, 134, 34-43. https://doi.org/10.1016/j.resconrec.2018.03.005

Jin, R., Yuan, H., \& Chen, Q. (2019). Science mapping approach to assisting the review of construction and demolition waste management research published between 2009 and 2018. Resources, Conservation and Recycling, 140, 175-188. https://doi.org/10.1016/j.resconrec.2018.09.029 
Johnston, R. B. (2016). Arsenic and the 2030 agenda for sustainable development. In Arsenic Research and Global Sustainability. Proceedings of the $6^{\text {th }}$ International Congress on Arsenic in the Environment (As 2016) (pp. 12-14).

Kearney, M. W. (2018). rtweet: Collecting Twitter Data. https://cran.r-project.org/web/packages/rtweet/ index.html

Khan, I. S., Ahmad, M. O., \& Majava, J. (2021, May 15). Industry 4.0 and sustainable development: A systematic mapping of triple bottom line, Circular Economy and Sustainable Business Models perspectives. Journal of Cleaner Production, 297, 126655. https://doi.org/10.1016/j.jclepro.2021.126655

Kirchherr, J., Reike, D., \& Hekkert, M. (2017). Conceptualizing the circular economy: An analysis of 114 definitions. Resources, Conservation and Recycling, 127, 221-232. https://doi.org/10.1016/j.resconrec.2017.09.005

Korhonen, J., Honkasalo, A., \& Seppälä, J. (2018a). Circular economy: The concept and its limitations. Ecological Economics, 143, 37-46. https://doi.org/10.1016/j.ecolecon.2017.06.041

Korhonen, J., Nuur, C., Feldmann, A., \& Birkie, S. E. (2018b) Circular economy as an essentially contested concept. Journal of Cleaner Production, 175, 544-552. https://doi.org/10.1016/j.jclepro.2017.12.111

Latour, B. (1987). Science in action: How to follow scientists and engineers through society. Harvard University Press.

Lewis, E. L., \& Linn, M. C. (1996). Where is the heat? A response to David Pushkin. Journal of Research in Science Teaching, 33(3), 335-337.

Lieder, M., \& Rashid, A. (2016). Towards circular economy implementation: A comprehensive review in context of manufacturing industry. Journal of Cleaner Production, 115, 36-51.

https://doi.org/10.1016/j.jclepro.2015.12.042

Lifset, R., \& Graedel, T. E. (2015). Industrial ecology. In J. D. Wright (Ed.), International encyclopedia of the social \& behavioral sciences ( $2^{\text {nd }}$ ed., pp. 843-853). Elsevier.

https://doi.org/10.1016/B978-0-08-097086-8.91023-7

Lindenfeld, L. A., Hall, D. M., McGreavy, B., Silka, L., \& Hart, D. (2012). Creating a place for environmental communication research in sustainability science. Environmental Communication, 6(1), 23-43. https://doi.org/10.1080/17524032.2011.640702

Loiseau, E., Saikku, L., Antikainen, R., Droste, N., Hansjürgens, B., Pitkänen, K., Leskinen, P., Kuikman, P., \& Thomsen, M. (2016). Green economy and related concepts: An overview. Journal of Cleaner Production, 139, 361-371. https://doi.org/10.1016/j.jclepro.2016.08.024

Lopes de Sousa Jabbour, A. B., Jabbour, C. J. C., Godinho Filho, M., \& Roubaud, D. (2018). Industry 4.0 and the circular economy: A proposed research agenda and original roadmap for sustainable operations. Annals of Operations Research, 270(1-2), 273-286.

https://doi.org/10.1007/s10479-018-2772-8

Lüdeke-Freund, F., Gold, S., \& Bocken, N. M. P. (2019). A review and typology of circular economy business model patterns. Journal of Industrial Ecology, 23(1), 36-61.

https://doi.org/10.1111/jiec.12763

Lyle, J. T. (1996). Regenerative design for sustainable development. John Wiley \& Sons.

Magrí, A., Giovannini, F., Connan, R., Bridoux, G., \& Béline, F. (2017). Nutrient management from biogas digester effluents: A bibliometric-based analysis of publications and patents. International Journal of Environmental Science and Technology, 14(8), 1739-1756.

https://doi.org/10.1007/s13762-017-1293-3

McDonough, W., \& Braungart, M. (2002). Cradle to cradle: Remaking the way we make things. North Point Press.

McDowall, W., Geng, Y., Huang, B., Barteková, E., Bleischwitz, R., Türkeli, S., Kemp, R., \& Doménech, T. (2017). Circular economy policies in China and Europe. Journal of Industrial Ecology, 21(3), 651-661. https://doi.org/10.1111/jiec.12597 
Michelini, G., Moraes, R. N., Cunha, R. N., Costa, J. M. H., \& Ometto, A. R. (2017). From linear to circular economy: PSS conducting the transition. Procedia CIRP, 64, 2-6. https://doi.org/10.1016/j.procir.2017.03.012

Moya-Clemente, I., Ribes-Giner, G., \& Chaves-Vargas, J. C. (2021). Sustainable entrepreneurship: An approach from bibliometric analysis. Journal of Business Economics and Management, 22(2), 297319. https://doi.org/10.3846/jbem.2021.13934

Mullen, L., Benoit, K., Keyes, O., Selivanov, D., \& Arnold, J. (2018). Fast, consistent tokenization of natural language text. Journal of Open Source Software, 3(23), 655. https://doi.org/10.21105/joss.00655

Naudé, M. (2011). Sustainable development in companies: Theoretical dream or implementable reality? Corporate Ownership and Control, 8(4), 352-364. https://doi.org/10.22495/cocv8i4c3art4

Nobre, G. C., \& Tavares, E. (2017). Scientific literature analysis on big data and internet of things applications on circular economy: A bibliometric study. Scientometrics, 111(1), 463-492. https://doi.org/10.1007/s11192-017-2281-6

Pauli, G. (2010). The blue economy: 10 years, 100 innovations, 100 million jobs. Paradigm Publications.

Pfeffer, J. (1993). Barriers to the advance of organizational science: Paradigm development as a dependent variable. Academy of Management Review, 18(4), 599-620. https://doi.org/10.5465/amr.1993.9402210152

Priem, J. (2014). Altmetrics. In B. Cronin \& C. R. Sugimoto (Eds.), Beyond bibliometrics: Harnessing multidimensional indicators of scholarly impact (pp. 263-288). The MIT Press.

Priem, J., \& Costello, K. L. (2010). How and why scholars cite on Twitter. Proceedings of the ASIST Annual Meeting, 47(1), 1-4. https://doi.org/10.1002/meet.14504701201

Priem, J., Piwowar, H. A., \& Hemminger, B. M. (2012, March 20). Altmetrics in the wild: Using social media to explore scholarly impact. http://arxiv.org/abs/1203.4745

Pulgarín, A. (2012). Dependence of Lotka’s law parameters on the scientific area. Malaysian Journal of Library and Information Science, 17(1), 41-50. http://mjlis.um.edu.my/index.php/MJLIS/article/ view/1881

Pushkin, D. B. (1996). A comment on the need to use scientific terminology appropriately in conception studies. Journal of Research in Science Teaching, 33(2), 223-224.

R Development Core Team. (2018). R: A language and environment for statistical computing. https://www.r-project.org/

Rajput, S., \& Singh, S. P. (2019). Connecting circular economy and industry 4.0. International Journal of Information Management, 49, 98-113. https://doi.org/10.1016/j.ijinfomgt.2019.03.002

Rajput, S., \& Singh, S. P. (2020). Industry 4.0 model for circular economy and cleaner production. Journal of Cleaner Production, 277, 123853. https://doi.org/10.1016/j.jclepro.2020.123853

Reuter, J., Pereira-Martins, J., \& Kalita, J. (2016). Segmenting Twitter hashtags. International Journal on Natural Language Computing, 5(4), 23-36. https://doi.org/10.5121/ijnlc.2016.5402

Richardson, J., Grose, J., Nelmes, P., Parra, G., \& Linares, M. (2016). Tweet if you want to be sustainable: A thematic analysis of a Twitter chat to discuss sustainability in nurse education. Journal of Advanced Nursing, 72(5), 1086-1096. https://doi.org/10.1111/jan.12900

Ruiz-Real, J. L., Uribe-Toril, J., Valenciano, J. D. P., \& Gázquez-Abad, J. C. (2018). Worldwide research on circular economy and environment: A bibliometric analysis. International Journal of Environmental Research and Public Health, 15(12), 2699. https://doi.org/10.3390/ijerph15122699

Russell-Rose, T., Lamantia, J., \& Makri, S. (2014). Defining and applying a language for discovery. In A. Nürnberger, S. Stober, B. Larsen, \& M. Detyniecki (Eds.), Lecture notes in computer science, Vol. 8382. Adaptive multimedia retrieval: Semantics, context, and adaptation (pp. 3-28). Springer. https://doi.org/10.1007/978-3-319-12093-5_1 
Saavedra, Y. M. B., Iritani, D. R., Pavan, A. L. R., \& Ometto, A. R. (2018). Theoretical contribution of industrial ecology to circular economy. Journal of Cleaner Production, 170, 1514-1522. https://doi.org/10.1016/j.jclepro.2017.09.260

Sager, J. C. (1990). A practical course in terminology processing. John Benjamins Publishing Company. https://doi.org/10.1075/z.44

Sartori, S., da Silva, F., \& Campos, L. M. S. (2011). Sustainability and sustainable development: A taxonomy in the field of literature. Ambiente \& Sociedade, 17(1), 1-22.

Schroeder, P., Anggraeni, K., \& Weber, U. (2019). The relevance of circular economy practices to the sustainable development goals. Journal of Industrial Ecology, 23(1), 77-95. https://doi.org/10.1111/jiec.12732

Segerson, K., Pearce, D. W., \& Turner, R. K. (1991). Economics of natural resources and the environment. Land Economics, 67(2), 272-276. https://doi.org/10.2307/3146419

Selivanov, D., \& Wang, Q. (2018). text2vec: Modern text mining framework for R. https://cran.r-project. org $/$ package $=$ text $2 \mathrm{vec}$

Shahzalal, M., \& Hassan, A. (2019). Communicating sustainability: Using community media to influence rural people's intention to adopt sustainable behaviour. Sustainability, 11(3), 812. https://doi.org/10.3390/su11030812

Sharmila, S. P., \& Sujatha, P. K. (2016). Segmentation based representation for tweet hashtag. In 2015 $7^{\text {th }}$ International Conference on Advanced Computing (ICoAC) (pp. 1-7). Chennai, India. IEEE. https://doi.org/10.1109/ICoAC.2015.7562804

Shen, K. W., Li, L., \& Wang, J. Q. (2020). Circular economy model for recycling waste resources under government participation: A case study in industrial waste water circulation in China. Technological and Economic Development of Economy, 26(1), 21-47. https://doi.org/10.3846/tede.2019.11249

Stahel, W. R. (2010). The performance economy. Palgrave Macmillan. https://doi.org/10.1057/9780230288843

Stankevičienè, J., \& Nikanorova, M. (2020). Eco-innovation as a pillar for sustainable development of circular economy. Business: Theory and Practice, 21(2), 531-544. https://doi.org/10.3846/btp.2020.12963

Su, B., Heshmati, A., Geng, Y., \& Yu, X. (2013). A review of the circular economy in China: Moving from rhetoric to implementation. Journal of Cleaner Production, 42, 215-227. https://doi.org/10.1016/j.jclepro.2012.11.020

Temmerman, R. (2000). Towards new ways of terminology description: The sociocognitive approach. John Benjamins Publishing Company. https://doi.org/10.1075/tlrp.3

Thelwall, M., Haustein, S., Larivière, V., \& Sugimoto, C. R. (2013). Do altmetrics work? Twitter and ten other social web services. PLoS ONE, 8(5), e64841. https://doi.org/10.1371/journal.pone.0064841

Todeschini, R., \& Baccini, A. (2016). Handbook of bibliometric indicators: Quantitative tools for studying and evaluating research. Wiley-VCH. https://doi.org/10.1002/9783527681969

Torres-Salinas, D., Cabezas-Clavijo, Á., \& Jiménez-Contreras, E. (2013). Altmetrics: New indicators for scientific communication in Web 2.0. Comunicar, 21(41), 53-60.

https://doi.org/10.3916/C41-2013-05

Tseng, M. L., Tan, R. R., Chiu, A. S. F., Chien, C. F., \& Kuo, T. C. (2018). Circular economy meets industry 4.0: Can big data drive industrial symbiosis? Resources, Conservation and Recycling, 131, 146-147. https://doi.org/10.1016/j.resconrec.2017.12.028

Türkeli, S., Kemp, R., Huang, B., Bleischwitz, R., \& McDowall, W. (2018). Circular economy scientific knowledge in the European Union and China: A bibliometric, network and survey analysis (20062016). Journal of Cleaner Production, 197, 1244-1261. https://doi.org/10.1016/j.jclepro.2018.06.118 
van Eck, N. J., \& Waltman, L. (2010). Software survey: VOSviewer, a computer program for bibliometric mapping. Scientometrics, 84(2), 523-538. https://doi.org/10.1007/s11192-009-0146-3

Veltri, G. A., \& Atanasova, D. (2017). Climate change on Twitter: Content, media ecology and information sharing behaviour. Public Understanding of Science, 26(6), 721-737. https://doi.org/10.1177/0963662515613702

Weller, K., Dröge, E., \& Puschmann, C. (2011). Citation analysis in Twitter: Approaches for defining and measuring information flows within tweets during scientific conferences. CEUR Workshop Proceedings, 718, 1-12.

Wijffels, J. (2018). udpipe: Tokenization, parts of speech tagging, lemmatization and dependency parsing with the "UDPipe" "NLP" Toolkit. https://cran.r-project.org/web/packages/udpipe/index.html

Yazan, D. M., \& Fraccascia, L. (2019). Sustainable operations of industrial symbiosis: An enterprise input-output model integrated by agent-based simulation. International Journal of Production Research, 58(2), 392-414. https://doi.org/10.1080/00207543.2019.1590660

Yuan, Z., Bi, J., \& Moriguichi, Y. (2006). The circular economy: A new development strategy in China. Journal of Industrial Ecology, 10(1-2), 4-8. https://doi.org/10.1162/108819806775545321 